\title{
Heavy metal recovery from the fine fraction of solid waste incineration bottom ash by wet density separation
}

\author{
Fabian Pienkoß ${ }^{1} \cdot$ Marco Abis $^{2} \cdot$ Martina Bruno $^{3} \cdot$ Raul Grönholm $^{4} \cdot$ Michel Hoppe $^{5} \cdot$ Kerstin Kuchta $^{2} \cdot$ Silvia Fiore $^{3}$. \\ Franz-Georg Simon ${ }^{1}$ (D)
}

Received: 6 August 2021 / Accepted: 2 November 2021 / Published online: 18 November 2021

(c) The Author(s) 2021

\begin{abstract}
This work is aimed at exploring the recovery of heavy metals from the fine fraction of solid waste incineration bottom ash. For this study, wet-discharged bottom ash fine-fraction samples from full-scale treatment plants in Germany and Sweden were analyzed. The potential for the recovery of heavy metal compounds was investigated through wet density-separation with a shaking table. The feed materials were processed without any pre-treatment and the optimum processing conditions were determined by means of design of experiments. Tilt angle and stroke frequency were identified as the most relevant parameters, and the optimum settings were $-7.5^{\circ}$ and $266 \mathrm{rpm}$, respectively. The obtained balanced copper enrichments (and yields) were $4.4(41 \%), 6.2$ (28\%) and 2.4 (23\%). A maximum copper enrichment of 14.5 with $2 \%$ yield was achieved, providing a concentrate containing $35.9 \mathrm{wt} . \%$ relevant heavy metal elements. This included $26.3 \mathrm{wt} . \%$ iron, $4.3 \mathrm{wt} . \%$ zinc and $3.8 \mathrm{wt}$.\% copper. In conclusion, density separation with shaking tables can recover heavy metals from bottom ash fine fractions. Medium levels of heavy metal enrichment (e.g., for $\mathrm{Cu} 2.7-4.4)$ and yield (Cu: 26-41\%) can be reached simultaneously. However, the separation performance also depends on the individual bottom ash sample.
\end{abstract}

Keywords Bottom ash · Density separation · Circular economy $\cdot$ Design of experiments

\section{Introduction}

In 2018, in Europe, almost 100 million tons of municipal solid waste (MSW) were thermally treated in 470 waste-toenergy plants producing circa 19 million tons of incineration bottom ash (BA) [1]. However, the reported BA treatment capacity in Europe is of 8.5 million tons [2]; hence, the majority of this fraction is either untreated or no information about recovery quota is given. Instead, processed BA undergoes different modular steps including screening and scalping operations, ferromagnetic removal of metal particles and other metal concentration steps [2].

BA from thermal waste treatment consists of solid phases as glass, ceramics, ash, and metals (ferrous, Fe and

Silvia Fiore

silvia.fiore@polito.it

1 BAM Bundesanstalt Für Materialforschung Und -Prüfung, Unter den Eichen 87, 12205 Berlin, Germany

2 SRWM (Sustainable Resource and Waste Management), Hamburg University of Technology, Blohmstr. 15, 21079 Hamburg, Germany

3 DIATI (Department of Engineering for Environment, Land, and Infrastructures), Politecnico Di Torino, corso Duca degli Abruzzi 24, 10129 Turin, Italy

4 Sysav Utveckling AB, 20025 Malmö, Sweden

5 Heidemann Recycling GmbH, 28277 Bremen, Germany

Kerstin Kuchta

kuchta@tuhh.de 
non-ferrous, NFe) already contained in the MSW, as well as new phases that are formed during the combustion process [3-6]. The five main chemical elements in BA are $\mathrm{Si}, \mathrm{Ca}$, $\mathrm{Fe}, \mathrm{Al}$, and $\mathrm{Na}$. While $\mathrm{Si}$ and $\mathrm{Ca}$ are bound as oxides and silicates, $\mathrm{Al}$ and $\mathrm{Fe}$ occur not only as oxides but also in their elemental form. $\mathrm{Na}$ is also present as chloride, $\mathrm{Ca}$ also as sulfate [7]. BA is an extremely inhomogeneous material, and its exact composition depends heavily on the type of waste incinerated, the conditions for incineration and further treatment steps $[3,8,9]$. A typical BA composition [3, 10-12] is:

- $9 \%$ inert material (glass, ceramics, stones etc.),

- $1 \%$ unburned (residual organic matter),

- $10 \%$ metals (8\% Fe metals and $2 \% \mathrm{NFe}$, mainly $\mathrm{Al}$ and $\mathrm{Cu}$ or $\mathrm{Cu}$ alloys),

- $40 \%$ ash and

- $40 \%$ melted products (slag).

Elemental metals are separated with magnets $(\mathrm{Fe})$ and eddy current separators (NFe) [13]. In specific, the separation of ferrous metals is generally applicable in situ and/or within the plant. Reasons for this include technology readiness, limited space demand, and the possibility to perform the separation on wet-discharged ash with high moistures [2]. Differently, the separation of NFe requires low moisture contents normally achieved in the BA by stockpiling, and in general, a higher number of processing steps. Hence, ex situ plants show higher recycling quota for $\mathrm{NFe}$, contrarily from in situ plants for which the Fe recovery yields are slightly higher [1,2].

$\mathrm{NFe}$ from BA are a valuable feedstock for the metallurgical industry [14]. The mineral fraction can be used as secondary building material if certain environmental requirements are fulfilled [15], specifically about the content of heavy metals and other impurities such as chloride and sulfate. Usually, an aging period of 6-20 weeks for carbonation resulting in reduced leaching of most heavy metals is commonly observed for bottom ash before using as building material [2]. Chlorides and lesser soluble sulfates can be removed to a large extent by wet-mechanical treatments [16]. Washing processes have been proven to be efficient in reducing leaching salts and heavy metals from aged BA [17]. However, chloride and sulfates are enriched in the washing water, so that recirculation is limited. Innovative treatments for the recovery of metals from BA have been proposed as wet processing directly after incineration [14] or as dry abrasion treatment to remove the superficial contamination of leaching salts [18]. The elemental composition and especially heavy metal concentrations of BA are variable; in the literature, the average content of copper is quoted with $3275 \mathrm{mg} / \mathrm{kg}$, but with a range from 738 to $17,620 \mathrm{mg} /$ $\mathrm{kg}$ [19]. Only elemental NFe can be recovered with eddy current separators, in today's practice down to a grain size of 2 or $4 \mathrm{~mm}$. NFe in the fine fraction and heavy metal compounds are not yet recovered from BA although the $0 / 2 \mathrm{~mm}$ fraction contains about half of the total amount of relevant metal species in about $25 \mathrm{wt} . \%$ of the total mass [20]. Here, additional measures in the treatment are required as investigated within this work. Since the density of heavy metal compounds is much higher than the density of the bulk ash $\left(2.6-2.7 \mathrm{~kg} / \mathrm{dm}^{3}\right.$, Table 2), density separation could be a viable approach. This was tested with moderate success in a study with a centrifugal concentrator [21] or a dry Wilfley shaking table $[22,23]$. Shaking tables are a state of the art technology applied to separation and concentration of valuable components from mixed materials, thus finding various applications from gold ore processing [24] to copper concentration from WEEE (waste from electric and electronic equipment) pyrolysis ashes [25]. The advantages and disadvantages of shaking tables are a high separation selectivity that, however, also limits capacity for sandy materials to about $2 \mathrm{t} / \mathrm{h}$ per full-sized deck [26]. As a result, they are often used as a final cleaning stage for already concentrated material feeds or for complex separation tasks [27]. To increase capacity and to make efficient use of the required floor space, decks can be arranged vertically with up to three levels. Another advantage is the possibility of direct adjustments to the process in case of visually distinguishable components, which, however, also increases the involvement of human operators [26]. Shaking tables can further be differentiated in wet tables and dry air tables. Although similarity is high between both types, air tables have an advantage for materials requiring a subsequent drying step after wet tabling. Drawbacks in turn are the emission of dust particles, the need of additional ventilation systems and also the higher need for operator attention due to required brushing of table surfaces [26].

Various cases for the general utilization of wet shaking tables are reported in the literature showing the large dependence of separation efficiency from the material to be treated. During the processing of complex tailings from chromite ore production, $\mathrm{Cr}_{2} \mathrm{O}_{3}$ was enriched by a factor of two with a total yield of 53\% [28], while $\mathrm{SnO}_{2}$ was enriched from a silicate matrix by a factor of 275 with a yield of $86 \%$ [29]. The other cases for the use of shaking tables are the recovery of gold from preconcentrated gravel plant outputs [30] and the enrichment of indicator elements for carbonatites containing niob, tantal and light rare-earth elements [31]. A sophisticated process for $0 / 2 \mathrm{~mm} \mathrm{BA}$ treatment with $8 \mathrm{t} / \mathrm{h}$ capacity was developed and successfully integrated in an existing BA wet-treatment plant by Brantner $\mathrm{GmbH}$ and Sepro Laboratories Inc. This process combines several aggregates such as a linear motion screen, gap separator, magnet separator, shaking table and falcon centrifuge. Target products are $200 \mathrm{~kg} / \mathrm{h}$ ferrous materials with $40-50 \mathrm{wt} . \%$ $\mathrm{Fe}$ and $70 \mathrm{~kg} / \mathrm{h} \mathrm{NFe}$ with a concentration of $80 \mathrm{wt} . \%$ [32]. 
Previous research investigated Wilfley shaking tables' applications for the collection of materials from mining activity, e.g., gold gravity concentration from virgin deposits [33], and from several waste streams: valuable metals' gravity concentration as pre-treatment for printed circuit boards' recycling [34] or $\mathrm{Cu}$ enrichment from ashes of e-waste pyrolysis [25]. Conversely, prior studies regarding valuable metal separation from MSW BA considered several techniques, often consequential from processing techniques of mined minerals [35]. Whereas, despite innovative methods, such as acid washing [36], microwave-assisted leaching [37] and X-ray fluorescence sorting [38] were proposed from recent studies, to our knowledge, an alternative approach to separation of valuable metals from BA through gravimetric shaking table remains still overlooked. Thereby, the aim of the present study is the investigation of valuable metals recovery from MSW incineration BA using a wet shaking table device to compliment the to-date underexploited $0 / 2 \mathrm{~mm}$ fraction of dry BA treatment facilities. Three fine BA samples (particle size below $2 \mathrm{~mm}$ ) were collected from full-scale treatment plants in two different European countries and characterized subsequently. Moreover, metals enrichment by gravity separation with the Wilfley shaking table has been modeled to investigate different operative conditions. In particular slope and tilt angle of table orientation, flowrate of process water, frequency, amplitude and spring tension of table vibration motion and feed rate of input BA material were considered.

\section{Materials and methods}

\section{Sample collection and preparation}

Three samples were obtained from BA treatment plants in Germany (A and B) and Sweden (C) between November 2018 and September 2019. All samples were generated by grate-type incineration plants operating at $850{ }^{\circ} \mathrm{C}$ and performing wet quenching of the originated residues, while aging was carried out at different conditions and durations. The processes applied on the BA involved sieving, magnetic separation and eddy current separation steps [20]. The collected samples belong to the category of fine BA, thereby their particle size was below $2 \mathrm{~mm}$ for plant $\mathrm{A}$ and $\mathrm{B}$ and below $4 \mathrm{~mm}$ for plant $\mathrm{C}$. Homogenization and splitting was performed using riffle boxes for samples A and B [39], and a Retsch rotating divider type PT100 for sample C. To maintain grain size strictly below $2 \mathrm{~mm}$, all samples were sieved prior to experimental activities. Additional information about the collected samples is summarized in Table 1.

\section{Equipment}

Density separation of BA was performed by wet processing using a shaking table from Holman-Wilfley (Model 800). The rectangular table deck had dimensions of $1280 \times 640 \mathrm{~mm}\left(0.8 \mathrm{~m}^{2}\right)$ and exhibited a straight and parallel riffle pattern with longitudinally decreasing riffle height. The feed of BA was introduced by means of a vibration channel device DR 100 from Retsch and the table inclination angles were determined with a DigiLevel Plus spirit level from Laserliner. The table was equipped with two variable area flowmeters from Georg Fischer (type 355) for washwater (300-3000 L/h) and feed-water (150-1500 L/h). Both flows were generated by submersible pumps from Sulzer (ABS Robusta 200 C) located in a basin for process water circulation. The five discharge pipes of the shaking table were combined in such manner, that a total of three fractions was collected: concentrates, middlings and tailings (Fig. 1).

Berlin tap water $(80 \mathrm{~kg})$ mixed with the wetting agent Netzer 53 (0.3 wt.\%, 240 g) from Petrofer Chemie H. R. Fischer was used as process water $(\mathrm{pH} 8.0 \pm 0.1,791 \pm 14 \mu \mathrm{S} /$ $\mathrm{cm})$ in a closed circuit.

Water-ash suspensions of mentioned fractions were collected on Retsch test sieves $(64 \mu \mathrm{m})$ located on top of buckets allowing outflow of water back to the basin. Prior and after the experiment process, water samples for anion analysis were collected from the basin, while $\mathrm{pH}$ and conductivity were measured inline (WTW Multi 3430). After process completion, sieves were dried at $80{ }^{\circ} \mathrm{C}$ for $24 \mathrm{~h}$ and remaining material on the table was discarded.

\section{Optimization of shaking table parameters}

The device is mainly composed of a flat and riffled table surface to which a slurry of feed material is introduced. Two different forces then act on the material resulting in separation according to density. Water is introduced together with feed material at one of the corners and also through a spraying pipe located at the long edge besides that corner. Since the table surface is inclined by two different angles,
Table 1 Characteristics of studied bottom ash samples

\begin{tabular}{llll}
\hline Sample & Origin & $\begin{array}{l}\text { MSW composition } \\
\text { (household:industry) }\end{array}$ & Aging \\
\hline A $(0 / 2 \mathrm{~mm})$ & Germany (north) & $40: 60$ & Indoor 2 month \\
B $(0 / 2 \mathrm{~mm})$ & Germany (east) & n.d & Outdoor $>4$ weeks \\
C $(0 / 4 \mathrm{~mm})$ & Sweden (south) & $50: 50$ & Outdoor 2.5 month \\
\hline
\end{tabular}



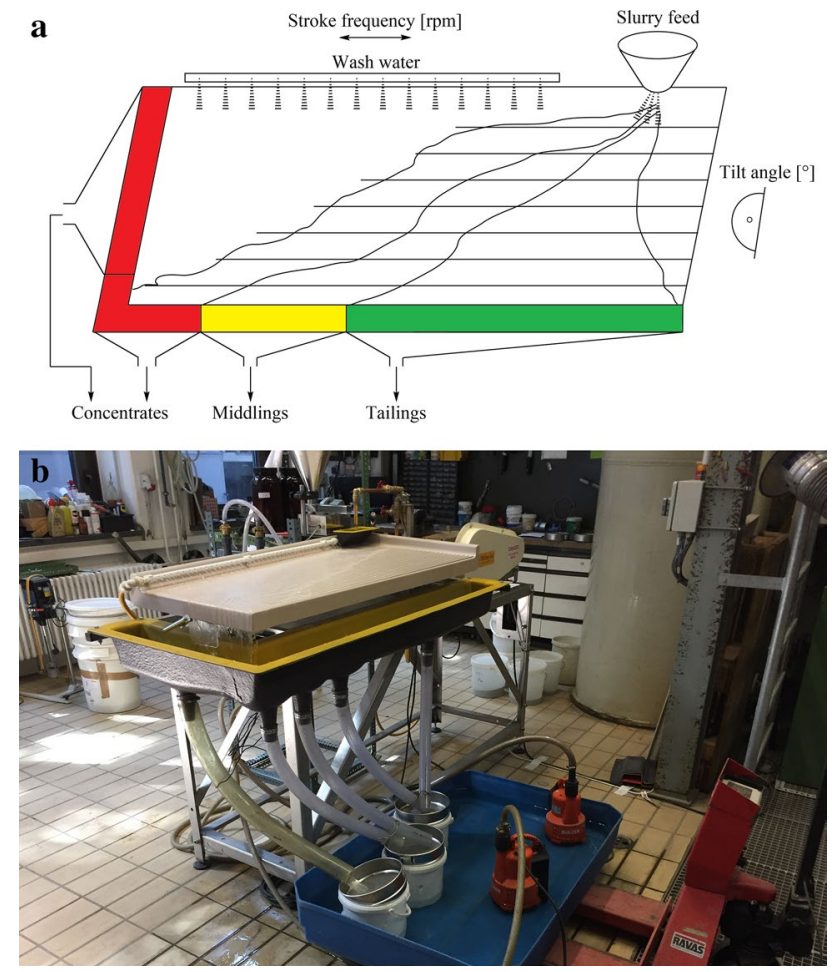

Fig. 1 Schematic representation (left) and photographic image (right) of the Wilfley table setup

this inclination determines, together with the flowrates of both pumps, the velocity of flowing water. Since there is also an increasing velocity of water flow concomitant with vertical distance to the table surface, these parameter settings result in larger particles flowing faster than smaller and lighter particles flowing faster than heavier. The second force is applied to particles through an oscillating motion of the table deck, parallelly directed to the longer edges. This motion has two effects. First is the translation of particles in the same direction and second a stratification of particles between the riffles according to density and size. Larger and less dense particles are enriched on top of the smaller and denser particles and are hence more likely washed away. The riffle height is decreasing with increasing distance from the feeding position and thus density of the remaining material increases. Both forces in combination result in diagonal spreading of the particles according to density [27].

To maximize the enrichment and yield of metals from BA, variable parameters of the Wilfley table were optimized using sample A. In total, eight parameters were adjustable. These were related to the table-surface orientation: (i) longitudinal and (ii) transversal inclination (slope and tilt); to the flowrates of process water: (iii) wash-water and (iv) feedwater; to the oscillating table motion: (v) stroke frequency, (vi) stroke amplitude, and (vii) spring tension; to the material input: (viii) feed-rate of BA. Wetting of the table surface is mandatory for this process. Due to this boundary condition, a constant slope of $-0.8^{\circ}$, maximum tilt of $-1.0^{\circ}$ and minimum stroke frequency of $144 \mathrm{rpm}(10 \%)$ were required. Regarding the process water flowrate, for washwater, $500 \mathrm{~L} / \mathrm{h}$ and for feedwater, $150 \mathrm{~L} / \mathrm{h}$ were required. The process water could have an influence on the cost of subsequent wastewater treatment. A reduction might be possible with steeper tilt angles. The loss of variation potential by constant process water flowrates is limited though, due to the interaction effect of flowrate and tilt angle [40]. Regarding the oscillating table motion, only stroke frequency turned out to be suitable for variation. Stroke amplitude and spring tension were hardly quantifiable by twisting of bolts or screws only. However, stroke frequency and amplitude are mutually dependent because at optimum conditions an increase in amplitude can be compensated by decreasing the frequency [40]. Accordingly, stroke amplitude was kept constant at a middle value of $10 \mathrm{~mm}$ while stroke frequency was varied over a broad range of 144-301 rpm (10-100\%), also presumed to be beneficial for fine particles [40]. The parameter of feed rate was intended for variation but turned out to exhibit low repeatability during initial tests. It was thus kept constant at the middle value of previous calibrations $(3.6 \mathrm{~kg} / \mathrm{h}, 50 \%)$.

The two remaining process parameters for optimization were tilt angle and stroke frequency. To find the ideal parameter settings and to model the two-dimensional design space, a design of experiments approach was pursued. For this purpose, a randomized I-optimal design with 15 runs was generated [41] and later augmented to tilt angles of $-9^{\circ}$ with three additional runs. The parameter of tilt angle was continuous $\left(-1\right.$ to $\left.-9^{\circ}\right)$ and set in intervals of $0.1^{\circ}$, the parameter of stroke-frequency in comparison only allowed discrete settings. Response values for modeling were: (i) mass yield of bottom ash, $R_{M}$ (Eq. 1), (i.) grain density $\left(\mathrm{kg} / \mathrm{dm}^{3}\right)$, (iii) enrichment factor of element concentration $i$ (Eq. 2) and (iv) valuables yield $R_{C}$ (Eq. 3) of respective elements:

$R_{M}=\frac{m_{K}}{m_{A}}$

$i=\frac{c_{K}}{c_{A}}$

$R_{C}=R_{M} \times i$

with $m_{K}$ being the mass of the obtained fraction, $m_{A}$ the mass of the feed, $c_{K}$ the respective element concentration in the obtained fraction, and $c_{A}$ the feed concentration of the respective element. Software for the design and modeling of experiments was Design-Expert Version 12 from Stat-Ease Inc. [42]. 


\section{Modeling of the process output}

During the modeling of response values introduced above, several models were generated per fraction: one model for $R_{M}$, one model for grain density and two models per element $\left(i\right.$ and $R_{C}$ ). In addition, a total mass balance model can be obtained by accumulation of the three $R_{M}$ Models. For calculating responses using analysis data of dried product materials, the mass of raw feed material was corrected for its moisture content of $8.4 \mathrm{wt} . \%$ in case of sample A.

\section{Analytical methods}

For analysis, dried and weighed samples were divided into subsamples with riffle boxes. Standard analysis of fractions from Wilfley table experiments was the determination of grain density with pycnometry (AccuPyc 1330 from Micromeritics) and elemental composition with XRF (X-ray fluorescence spectroscopy; Xepos Benchtop from Spectro Analytical Instruments). The preparation of samples for $\mathrm{XRF}$ analysis was done by milling and subsequent analysis of the powders. With a sample size of $10 \mathrm{~g}$ (sample number: three), a standard deviation of about $10 \%$ was reached. Further analytical methods for the determination of ion, carbonate and moisture contents, polymer identification, bulk density, loss on ignition, $\mathrm{pH}$, conductivity and microscopy are described in the supporting information (S 1.1).

\section{Results and discussion}

\section{Characterization of input materials}

The input materials $(0 / 2 \mathrm{~mm})$ for shaking table experiments were evaluated by collection of the dried-material screening curves. Furthermore, obtained sieve fractions were analyzed regarding elemental composition and grain density (Fig. 2).

Samples A and $\mathrm{C}$ exhibited almost identical screening curves $\left(\mathrm{d}_{50}=0.72 \mathrm{~mm}\right)$ that might be derived from comparable input materials and firing conditions. Sample B in comparison was finer $\left(\mathrm{d}_{50}=0.54 \mathrm{~mm}\right)$. Concerning the grain densities of sieving fractions, deviations between sample A and B were small. For the interval, 0/0.063 mm values of $2.5-2.6 \mathrm{~kg} / \mathrm{dm}^{3}$ were found, that gradually increased with particle size to values of $2.7-2.8 \mathrm{~kg} / \mathrm{dm}^{3}$ for $1.25 / 2.00 \mathrm{~mm}$. In the contrary, sample $\mathrm{C}$ from Sweden exhibited a significantly lower level of grain density increasing from 2.3 to $2.7 \mathrm{~kg} / \mathrm{dm}^{3}$ for the previously mentioned range.

Regarding target element contents, sample A exhibited the highest levels, sample B medium levels and sample C low levels. The concentrations of copper and zinc were generally decreasing with particle size, iron contents increased. While deviations in element concentration were small for
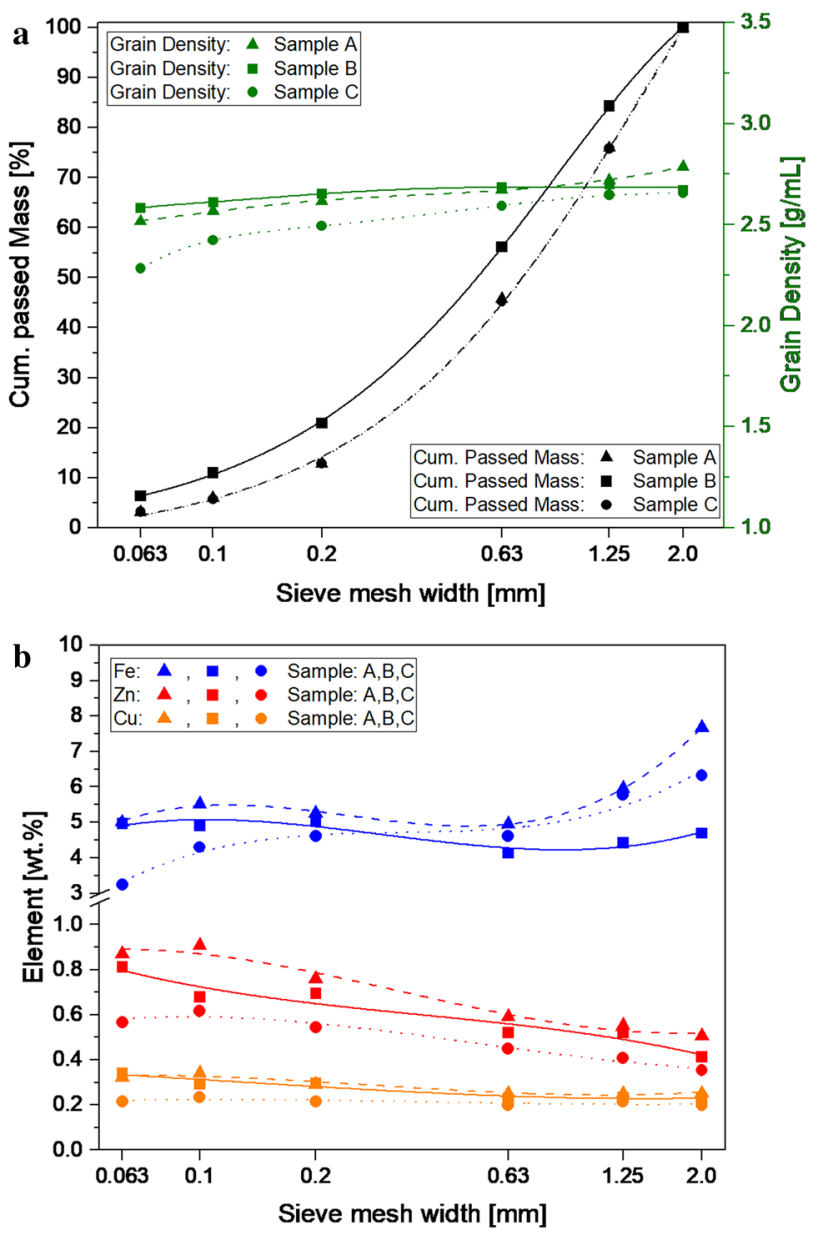

Fig. 2 Results of the sieving analyses according to sieve intervals; left: cumulated mass passing and grain density, right: elemental content of $\mathrm{Fe}, \mathrm{Zn}$ and $\mathrm{Cu}$

copper, they increased for zinc and were highest for iron. Notably, sample B exhibited smaller particles and higher densities than the other two samples with a medium content of target elements. Table 2 summarizes additional parameters for the characterization of studied BA samples.

The driest material was Sample B which was sampled earliest and stored indoors in an open big bag with air contact, explaining the high carbonate content indicating the degree of carbonation [43]. For each density separation experiment with sample $\mathrm{A}$, an average of $1.5 \mathrm{~kg}$ was treated, utilizing $80 \mathrm{~L}$ of recirculated process water. Liquid samples were taken to evaluate the increase of sulfate and chloride concentrations in comparison to fresh water. Averaged over all experiments, the increase of chloride and sulfate concentrations was $95 \pm 8 \mathrm{mg} / \mathrm{L}$ and $50 \pm 14 \mathrm{mg} / \mathrm{L}$. Conductivity and $\mathrm{pH}$ in turn were measured over time and average values at the plateau phase after $30 \mathrm{~min}$ were $1143 \pm 25 \mu \mathrm{S} / \mathrm{cm}$ and $\mathrm{pH} 8.9 \pm 0.1$ starting from freshwater values of $791 \pm 14 \mu \mathrm{S} /$ $\mathrm{cm}$ and $\mathrm{pH} 8.0 \pm 0.1$. 
Table 2 Additional parameters for the characterization of studied bottom ash samples

\begin{tabular}{llll}
\hline Parameter & Sample A & Sample B & Sample C \\
\hline Moisture [wt.\%] & $8.4 \pm 0.4^{3^{*}}$ & $3.1 \pm 0.6^{3^{*}}$ & $11.5 \pm 0.4^{5^{*}}$ \\
$\begin{array}{l}\text { Grain density [kg/ } \\
\text { dm }{ }^{3} \text { ] }\end{array}$ & $2.7^{2^{*}}$ & $2.7^{2^{*}}$ & $2.6^{2^{*}}$ \\
Bulk density [t/m $\left.\mathrm{m}^{3}\right]$ & $1.06 \pm 0.01^{3^{*}}$ & $1.12 \pm 0.003^{3^{*}}$ & $1.02 \pm 0.03^{3^{*}}$ \\
Total porosity [\%] & 0.03 & 0.09 & 1.21 \\
Loss on ignition & $5.2^{2^{*}}$ & $6.8^{2^{*}}$ & $13.3^{2^{*}}$ \\
$\quad$ [wt.\%] & & & \\
Carbonate [wt.\%] & $6.0^{2^{*}}$ & $9.3^{3^{*}}$ & $6.7^{2^{*}}$ \\
Conductivity [mS/cm] & $5.8^{2^{*}}$ & $6.9^{2^{*}}$ & $4.0^{2^{*}}$ \\
pH [] & $10.9^{2^{*}}$ & $9.7^{2^{*}}$ & $10.9^{2^{*}}$ \\
Fe [wt.\%] & $5.63 \pm 0.25^{7^{*}}$ & $4.64 \pm 0.11^{8^{*}}$ & $5.37 \pm 0.21^{7^{*}}$ \\
$\mathrm{Zn}$ [wt.\%] & $0.61 \pm 0.02^{7^{*}}$ & $0.58 \pm 0.02^{8^{*}}$ & $0.45 \pm 0.01^{7^{*}}$ \\
Cu [wt.\%] & $0.26 \pm 0.01^{7^{*}}$ & $0.26 \pm 0.02^{8^{*}}$ & $0.21 \pm 0.02^{7^{*}}$ \\
\hline
\end{tabular}

$\mathrm{x}^{*}$-fold measurement

During initial experiments with sample A, parts of the BA material were observed to swim on top of the water surface thus hindering efficient wet processing. To solve this problem, a low-foaming wetting agent was used with 0.3 wt. $\%$ in the process water (Netzer 53, see above). The floating material appeared to consist of ash conglomerates, pulp, wood, and possibly wool insulation. Another observation was made with regard to the tailing fractions containing visible particles of microplastic, previously described by Yang et al. [44]. Microplastic was isolated manually with a tweezer when appearing to the eye. The lower boundary of microplastic occurrence in sample A was determined by weighing of collected particles (size $<2 \mathrm{~mm}$ ) as $4.6 \mathrm{mg}$ / $\mathrm{kg}(0.12 \mathrm{~g}$ in $25.9 \mathrm{~kg})$. ATR-IR (attenuated total reflection infrared) spectroscopy was used to identify these particles as high-density polyethylene, isotactic polypropylene, and polyethylene-terephthalate.

\section{Modeling of the process output}

Figure 3 shows the models for mass yield $\left(R_{M}\right)$ according to fraction together with the total mass balance as contour plots. Models of mass yield showed clear patterns according to the set values of tilt angle and stroke frequency. For the concentrate fraction (top left), $R_{M}$ was below $20 \%$ for more than half of the design space. To achieve a higher $R_{M}$, tilt angles above $-2.0^{\circ}$ were required at stroke frequencies of $144 \mathrm{rpm}$, while at $301 \mathrm{rpm}$, a tilt angle above $-7.0^{\circ}$ was sufficient. In general, the mass yield for this fraction was enlarged with at the same time increased parameter settings for tilt angle and stroke frequency, which both contributed with similar sized model coefficients. An opposite behavior was observed for $R_{M}$ of the tailings fraction (bottom left), while the middlings fraction (top right) filled the gap between the two previous models. Regarding the total mass balance (bottom right), for most parameter combinations, 80-94\% was achieved since only small amounts of BA usually remained on the table. However, for comparable low stroke frequencies and high tilt angles, table residues increased to a maximum of about 30\%. In Fig. 4, the models for grain density are shown according to fraction.

During Wilfley table experiments, the physical property of grain density was exploited to achieve an enrichment of heavy metal species in the concentrate fraction. The BA used for this process exhibited a bulk grain density of $2.7 \mathrm{~kg} / \mathrm{dm}^{3}$ which thus marks the threshold for enrichment or depletion. Considering the concentrate fraction, the majority of parameter settings lead to increased grain densities of up to $3.6 \mathrm{~kg} / \mathrm{dm}^{3}(+33 \%)$, confirming the desired effect of density separation. In comparison to the linear $\mathrm{R}_{\mathrm{M}}$ model of concentrates, this model was quadratic and largely dominated by the coefficient of $\mathrm{B}^{2}$ (tilt angle ${ }^{2}$ ) expressed by a quadratic increase of density concomitant to tilt angle. The grain density model for middlings fraction was similar to the concentrate model but required lower values of tilt angle $\left(<-5^{\circ}\right)$ to achieve grain densities above the $2.7 \mathrm{~kg} / \mathrm{dm}^{3}$ threshold. Considering the respective model of tailings fraction, all parameter combinations lead to values below $2.7 \mathrm{~kg} / \mathrm{dm}^{3}$. At the example of copper as an industrial relevant metal, the models for its enrichment and yield from the starting material are shown in Fig. 5.

Enrichment of copper is achieved when the concentration is higher in comparison to the starting material (0.26 wt.\%). For the concentrate fraction model (top left), this was achieved over almost the whole design space and the maximum was reached at a tilt angle of $-7.7^{\circ}$ with an enrichment of eightfold to $2.05 \mathrm{wt} . \%$. With attention to the grain density model of the same fraction (Fig. 4 top left), a correlation between both responses becomes obvious. In addition, both models are quadratic and mainly dependent on the factor of tilt angle. Considering the middlings fraction model (top mid), the area with high enrichments is largely decreased. However, at the minimum of tilt angle $\left(-9^{\circ}\right)$ and stroke frequency $(144 \mathrm{rpm})$, the highest observed enrichment of $i=15$ (3.76 wt.\%) was reached. This fraction is viewed with more detail in the following sections. In contrast, the tailings fraction model (top right) was an even plane with a depletion of $0.85 \pm 0.05$. The share of recoverable copper from the starting material is of equal importance. Copper yield models (Fig. 5 bottom row) are largely dominated by the models of general mass yield from Fig. 3. However, when attention is paid to the contour line of $R_{M}=5 \%$ in Fig. 3 top left and $R_{C}=5 \%$ Fig. 5 bottom left, a significant deviation is manifested. Mentioned $R_{C}$ line is shifted towards the bottom left corresponding to an enrichment of copper.

Discussed models were created by the analysis of elemental copper contents of fractions. However, samples may 

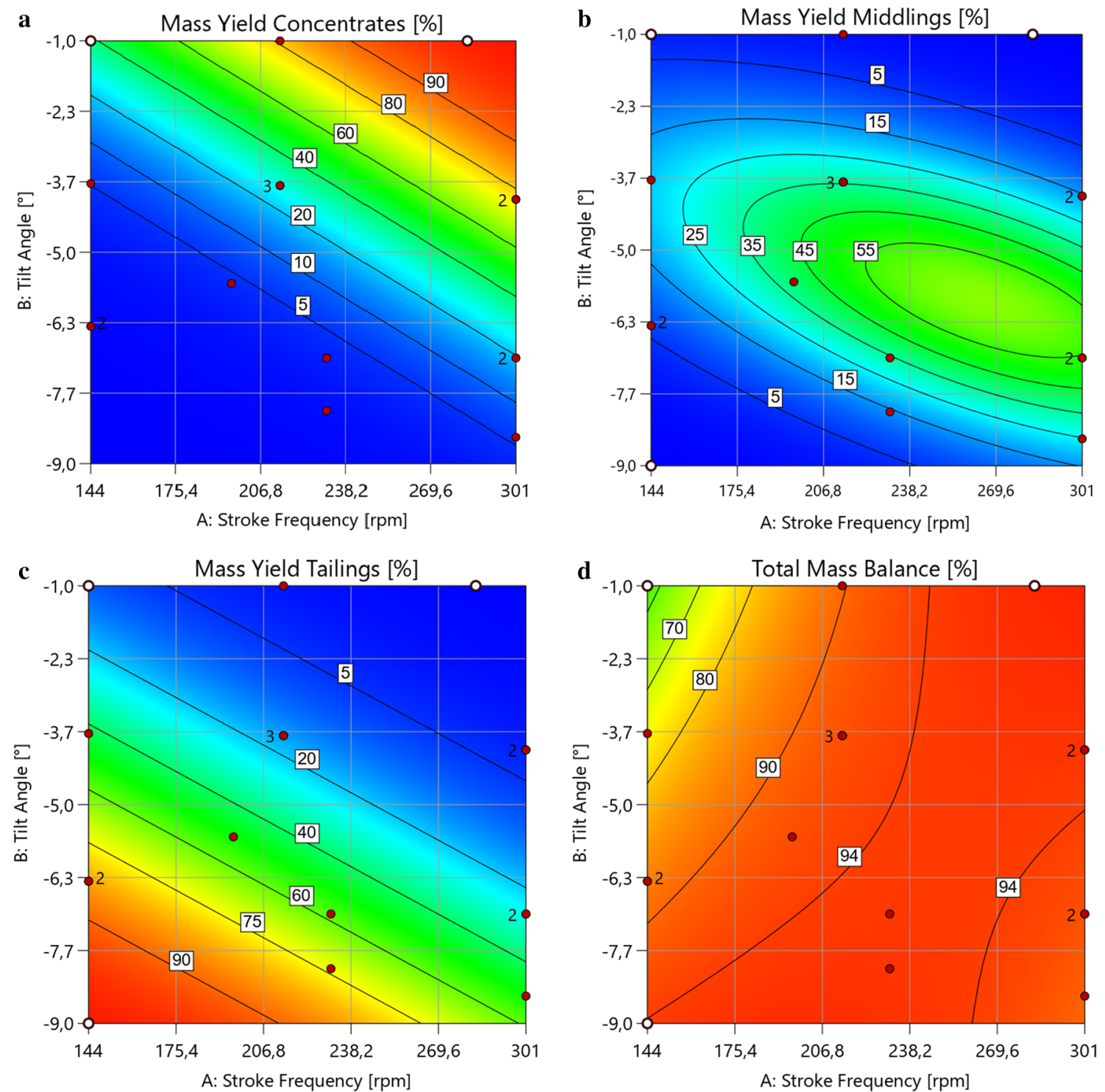

Fig. 3 Contour plots for the models of mass yield together with the total mass balance of sample A: mass yield of concentrates (a), middlings (b), tailings (c) and total mass balance (d). Color gradient range 0-100 wt.\%

contain metallic copper, copper chalcogenides, halides and other species. Considering that the general copper content of the feed material was $0.26 \pm 0.01 \mathrm{wt} . \%$ and that the tailing fractions after processing still contained $0.22 \pm 0.01 \mathrm{wt} . \%$ copper in average, a certain portion of copper may not be recoverable by density separation. The contour plots for iron and zinc enrichment follow the example of copper and are summarized in the supporting information (Fig. S1).

\section{Optimization of copper enrichment and yield}

Regarding the processing of BA, both responses enrichment and element yield require simultaneous maximization. To illustrate this question of optimization in Fig. 6 (left), both values are plotted together for all experiments and fractions at the example of copper.

As previously mentioned, the maximum copper enrichment of 14.5 was reached with the middlings fraction. However, copper yield is only at $2.0 \%$ for this experiment since both responses are inversely correlated. Reasonable compromise is needed accordingly. An optimum combination of both responses is reached for data points located towards the top right of Fig. 6 left, which is best fulfilled by the concentrate fraction (dense line). As indicated by horizontal and vertical lines, a balanced output would be an enrichment of 5.0 with $35 \%$ yield, i.e., at least one-third of the total amount of present copper with a mid-single-digit level of enrichment is achieved. Since models were created for both responses, simultaneous 

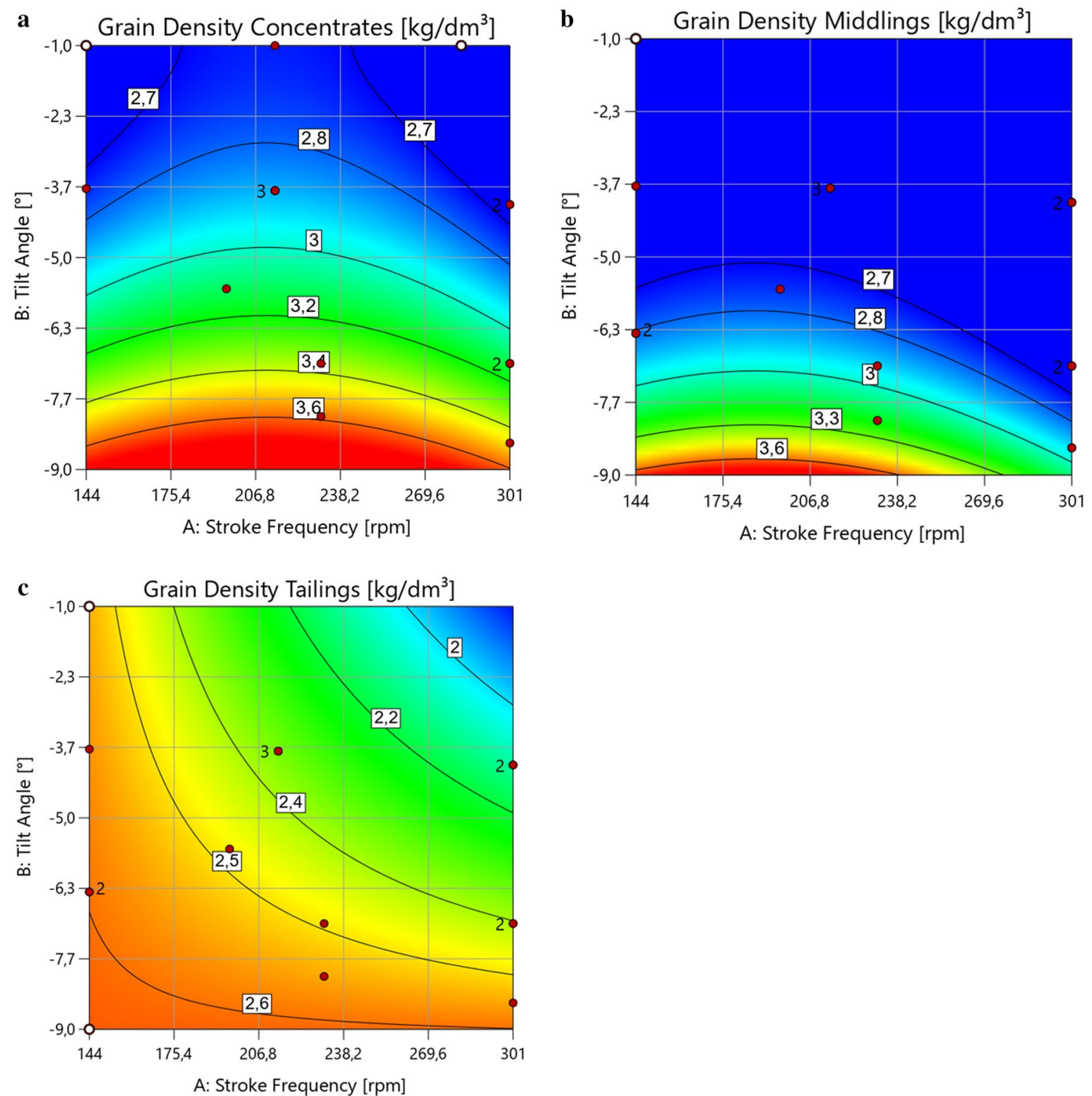

Fig. 4 Contour plots for the grain density models of sample A: grain density of concentrates (a), middlings (b) and tailings (c). Color gradient range top: $2.7-3.7 \mathrm{~kg} / \mathrm{dm}^{3}$, bottom: $1.8-2.7 \mathrm{~kg} / \mathrm{dm}^{3}$

optimization can be performed to identify the required settings of tilt angle and stroke frequency. Selected parameter range for this optimization was an enrichment of 4-6 and a yield of 20-45\% (grey rectangle). Numerical optimization then suggested settings of $266 \mathrm{rpm}$ and $-7.5^{\circ}$ to achieve an enrichment of 5.0 with $25 \%$ yield (Fig. 6, right, yellow area). An actual experiment with these software-generated parameter settings resulted in an enrichment of 4.4 at a yield of $41.4 \%$ (cross (+) in Fig. 6, left).

\section{Assessment of metal enrichment and yield}

Processing conditions found in the previous subsection were used for a comparison of the output generated with all three samples (Table 3).

Focusing on copper, achieved enrichment was highest for sample B $(i=6.2)$ which also exhibited the smallest particle sizes $\left(d_{50}=0.54 \mathrm{~mm}\right)$ and highest level of grain density (Fig. 2 left). Likewise, this sample achieved the 

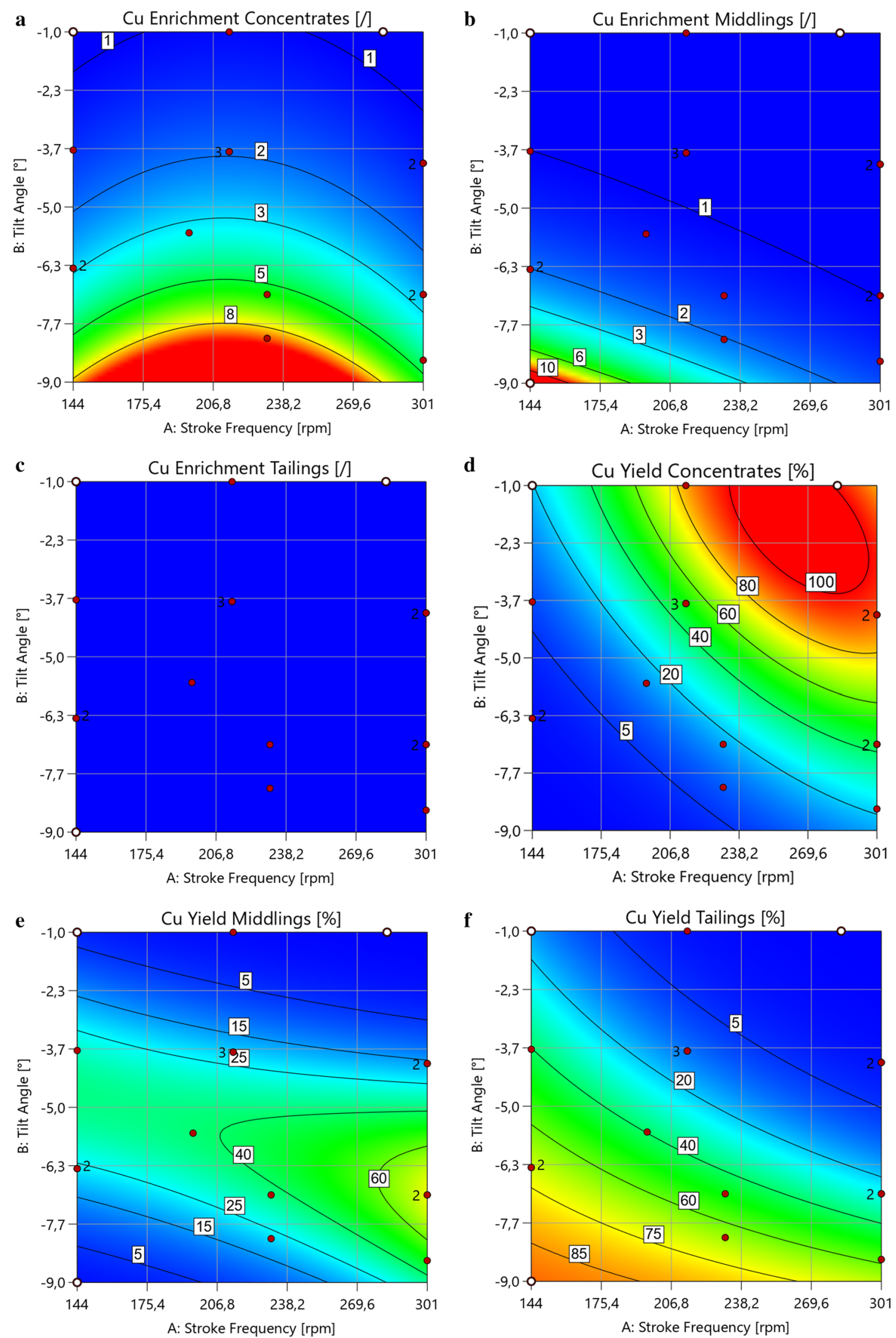

Fig. 5 Contour plots for the copper enrichment (a: concentrates, b: middlings and $\mathbf{c}$ : Tailings) and copper yield (d: concentrates, e: middlings and f: tailings) of sample A. Color gradient ranges top (a-c): 1-10, bottom (d-f) 0-100 wt.\% 

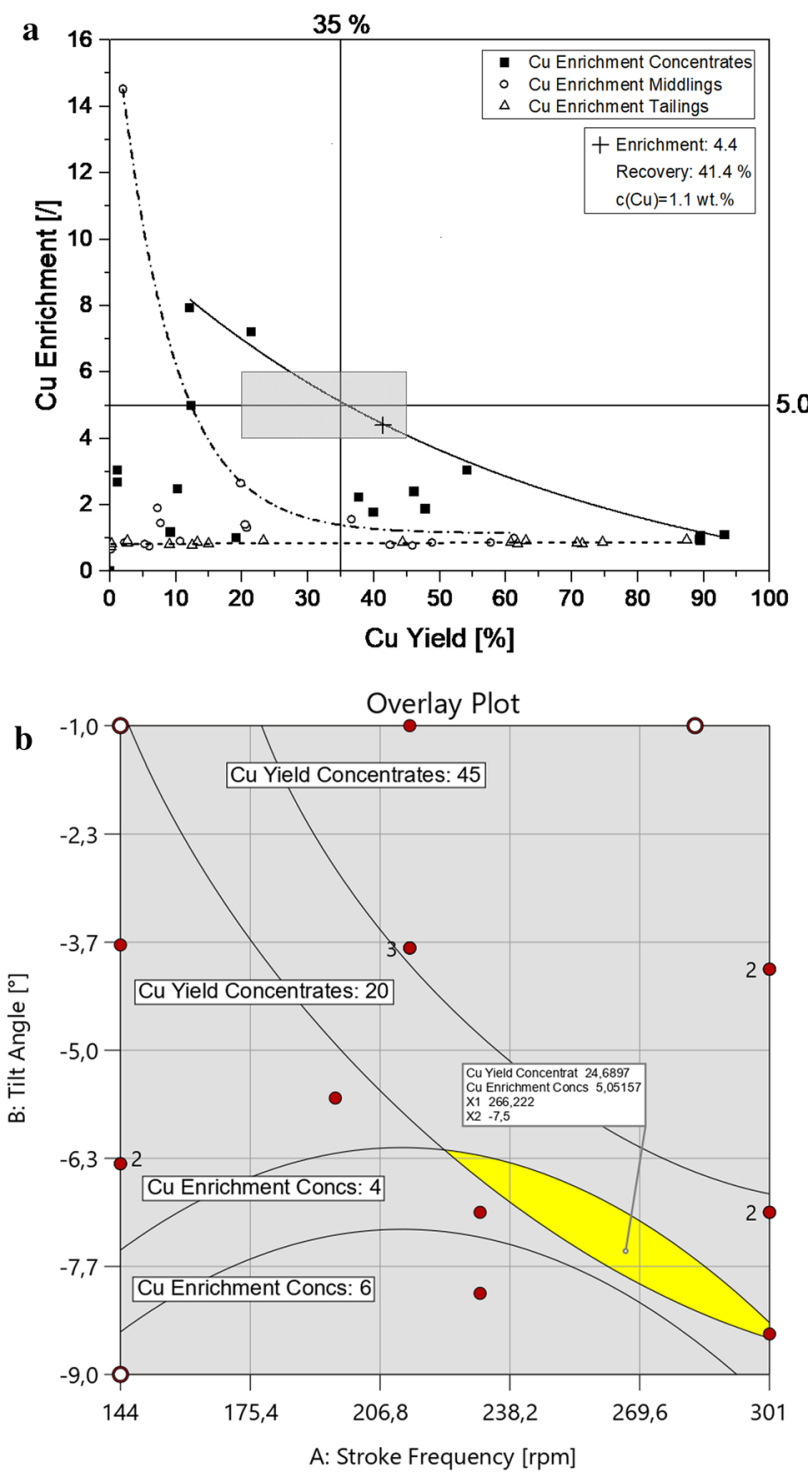

Fig. 6 Point cloud for all obtained copper enrichments and yields of sample A (left) together with an overlay plot for the optimization of both responses (right), the yellow area marks parameter settings yielding the targeted response values

highest copper depletion in the tailings fraction with $i=0.7$ which was at $0.8 \pm 0.05$ for sample A and C. In comparison, both of these samples exhibited significantly larger particles $\left(d_{50}=0.72 \mathrm{~mm}\right)$ and a lower enrichment of copper. In conclusion, lower values of $d_{50}$ and a possibly higher degree of liberation might enhance the enrichment of copper. Additional conclusions regarding samples $\mathrm{A}$ and $\mathrm{C}$ with similar particles size are difficult to draw. Among both, sample A exhibited the higher copper enrichment (4.4 vs. 2.4) and at the same time higher grain density (2.7 vs. $2.6 \mathrm{~kg} / \mathrm{dm}^{3}$ ) and lower loss on ignition (5.2 vs. 13.3 wt.\%). Sample C from Sweden might thus contain a larger share of organic material that decreases grain density. In case of composite formation with other particles, a negative effect towards density separation might result. Sample C further exhibited a higher moisture content (11.5 vs. $8.4 \mathrm{wt} . \%)$ and higher porosity (1.21 vs. $0.03 \%)$ than sample A. However, the achieved enrichments for zinc and iron are higher for sample $\mathrm{C}$ than for sample A. Regarding yields no general statements can be concluded. IN addition, indoor versus outdoor aging did not result in significant differences towards density separation. The individually heterogeneous and complex BA samples behave differently during processing on a shaking table.

A similar study for BA density separation was performed by Back et al. [22, 23]. Used material in this case was the $0 / 8 \mathrm{~mm}$ fraction from a dry discharge system, which in turn should exhibit less oxidized and less chemically altered components. The material was processed in a multi-step approach of sieving, removal of magnetics and individual treatment of sieving fractions on a dry air-table. Based on the combination of individual experimental results, theoretical scenarios were created for the $0.5 / 8 \mathrm{~mm}$ material leading to calculated maxima for copper of $i=7.1$ and $R_{C}=39 \%$ [22]. For an improved comparison, we used the published data to calculate copper enrichment and yield for the $0.5 / 2 \mathrm{~mm}$ air table concentrate. For this scenario, copper enrichment was $i=3.8$ with a yield of $R_{C}=60 \%$. Results are thus in a comparable region as for the wet tabling of sample A with $i=4.4$ and $R_{C}=41 \%$, keeping in mind that dry discharge material should exhibit higher density differences between metal and matrix and also, that during dry tabling of $0 / 2 \mathrm{~mm}$ bulk-material separation efficiency might decrease.
Table 3 Achieved metal enrichment and yield according to bottom ash sample; conditions: $266 \mathrm{rpm}$ stroke frequency, $-7.5^{\circ}$ tilt angle

\begin{tabular}{|c|c|c|c|c|c|c|c|c|c|}
\hline \multirow[t]{3}{*}{ Element } & \multicolumn{3}{|c|}{ Enrichment $i[]$} & \multicolumn{3}{|c|}{ Yield $R_{c}[\%]$} & \multicolumn{3}{|c|}{ Concentration c [wt.\%] } \\
\hline & \multicolumn{3}{|c|}{ Sample } & \multicolumn{3}{|c|}{ Sample } & \multicolumn{3}{|c|}{ Sample } \\
\hline & A & B & $\mathrm{C}$ & A & B & C & A & B & C \\
\hline Copper & 4.4 & 6.2 & 2.4 & 41 & 28 & 23 & 1.1 & 1.6 & 0.5 \\
\hline Zinc & 2.8 & 3.9 & 3.3 & 27 & 18 & 33 & 1.7 & 2.3 & 1.5 \\
\hline Iron & 2.7 & 2.9 & 3.0 & 26 & 14 & 30 & 15.2 & 13.6 & 16.1 \\
\hline
\end{tabular}




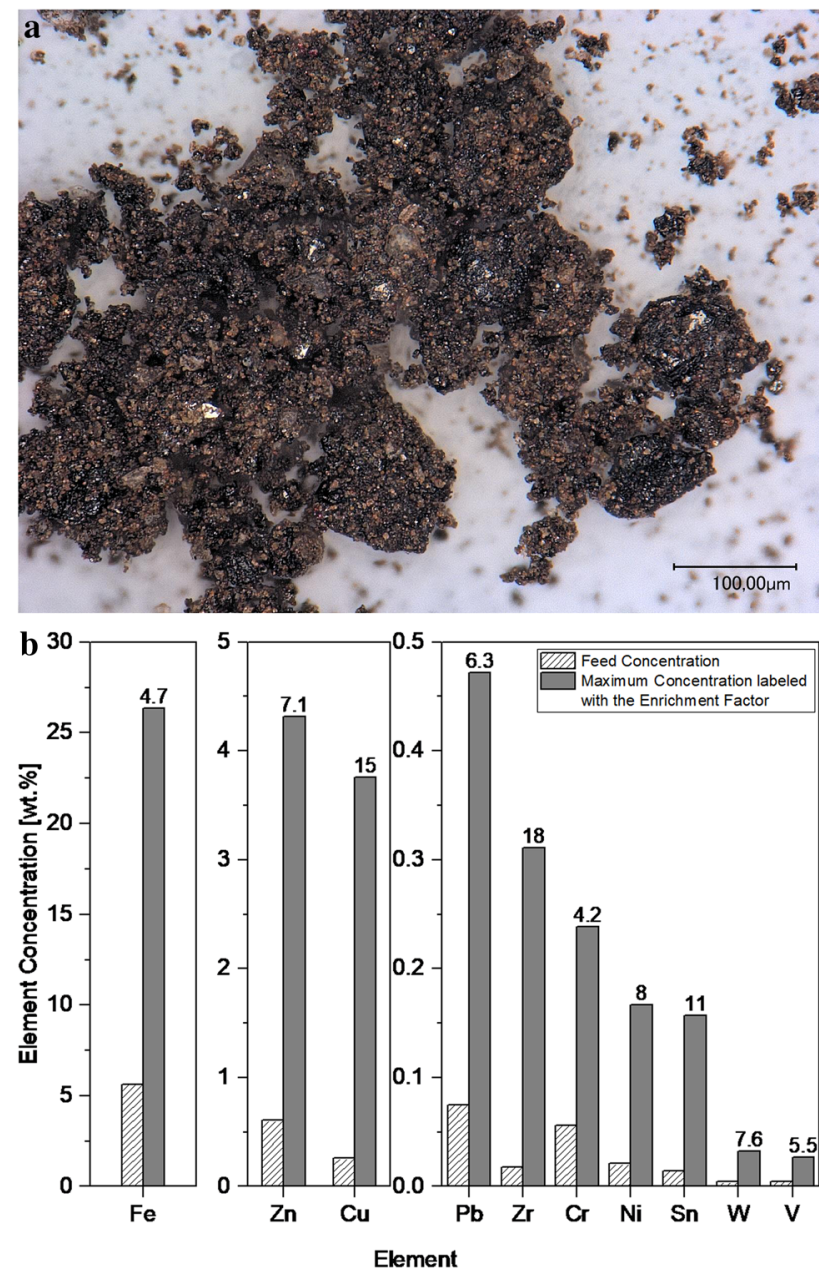

Fig. 7 Image of the metal concentrate obtained from sample A (left) and its corresponding elemental composition with enrichment factors (right)

\section{Assessment of the metal concentrate}

As already mentioned, one certain run produced an exceptionally high copper enrichment of 15 . This material was analyzed further to gain additional information.

With attention to the details of the microscope image (Fig. 7, left), certain light reflecting metallic surfaces can be identified besides red-brown copper like particles. The general material, however, exhibits a russet and black color.

Further characterization was performed by means of XRD (X-Ray diffraction) allowing phase identification and quantification of crystalline phases with portions larger than $5 \mathrm{wt} . \%$. Analysis revealed a content of $37.5 \mathrm{wt} . \%$ quartz, 26.8 wt. $\%$ wuestite, 22.8 wt. $\% \mathrm{Fe}_{3} \mathrm{O}_{4}$ and 12.9 wt. $\% \mathrm{Fe}_{2} \mathrm{O}_{3}$ summing up to in total $62.5 \mathrm{wt} \%$ of different iron oxide phases. The results of XRF spectroscopy are summarized in Fig. 7 right. Elemental composition was 26.3 wt.\% iron, 4.3 wt.\% zinc, 3.8 wt.\% copper, 0.5 wt.\% lead, 0.3 wt.\% zirconium, 0.2 wt.\% chromium, 0.2 wt.\% nickel, 0.2 wt.\% tin, 0.03 wt. $\%$ tungsten and 0.03 wt. $\%$ vanadium, summing up to $35.86 \mathrm{wt} . \%$ relevant metals. The elements silicon (11.2 wt.\%), aluminum (1.1 wt.\%) and calcium (5.3 wt.\%), derived from slags and calcinated lime comprised $17.6 \mathrm{wt} . \%$ in comparison. Since the untreated feed material comprised $29.2 \mathrm{wt} . \%$ of elements from the second group and solely 6.7 wt.\% from the first group, this relates to an average enrichment of 5.3 for group one (heavy metals) and an average depletion of 0.6 for group two (slags). Further information regarding the overall maxima of achieved enrichment and depletion from all experiments can be found in the supporting information (Fig. S2 and Table S1). To gain information about the distribution of elements within the sample and the possible presence of alloys such as brass or stainless steel, SEM-EDX (scanning electron microscope; energy-dispersive X-Ray) mapping was performed (Fig. 8).

Obtained images can be sorted into three categories. First, the elements with content $>5 \mathrm{wt} . \%$ iron, silicon and calcium (row 1 ). They are widely spread as fine spots and also exhibit a relatively high number of large to medium particles with dense element frequency. The second group comprises copper, zinc and manganese (row 2), which are also widely spread as fine spots next to less frequent and medium-sized particles. The last group of aluminum, titanium and chromium (row 3) again exhibits a greater number of concentrated spots with medium sizes, but simultaneously a low presence of small spots. In summary, elements are both present in fine spread small spots and in larger concentrated particles. In addition, no certain species were identified by comparison of elemental maps for metals and anions such as chloride and sulfur. Since the actual material was present as a fine powder and XRD only identified oxides, this species might be the predominant form.

\section{Conclusions}

Density separation for heavy metal recovery from BA fine fractions was evaluated using samples from full-scale BA treatment plants in Germany and Sweden. For the assessment of this technology at lab-scale, a wet shaking table was employed, and samples were processed without any pretreatment. The process parameters' stroke frequency and tilt angle were identified as most relevant and used for a detailed design of experiments' optimization study. Heavy metal enrichment is associated with a spike in grain density, and both are positively correlated with an increase in tilt angle while stroke frequency is less relevant. Valuables yield in comparison depends on both process parameters to a similar extend and is enlarged with increased parameter settings. However, enrichment and yield are inversely correlated and require balancing. Modeling of the design space for both 

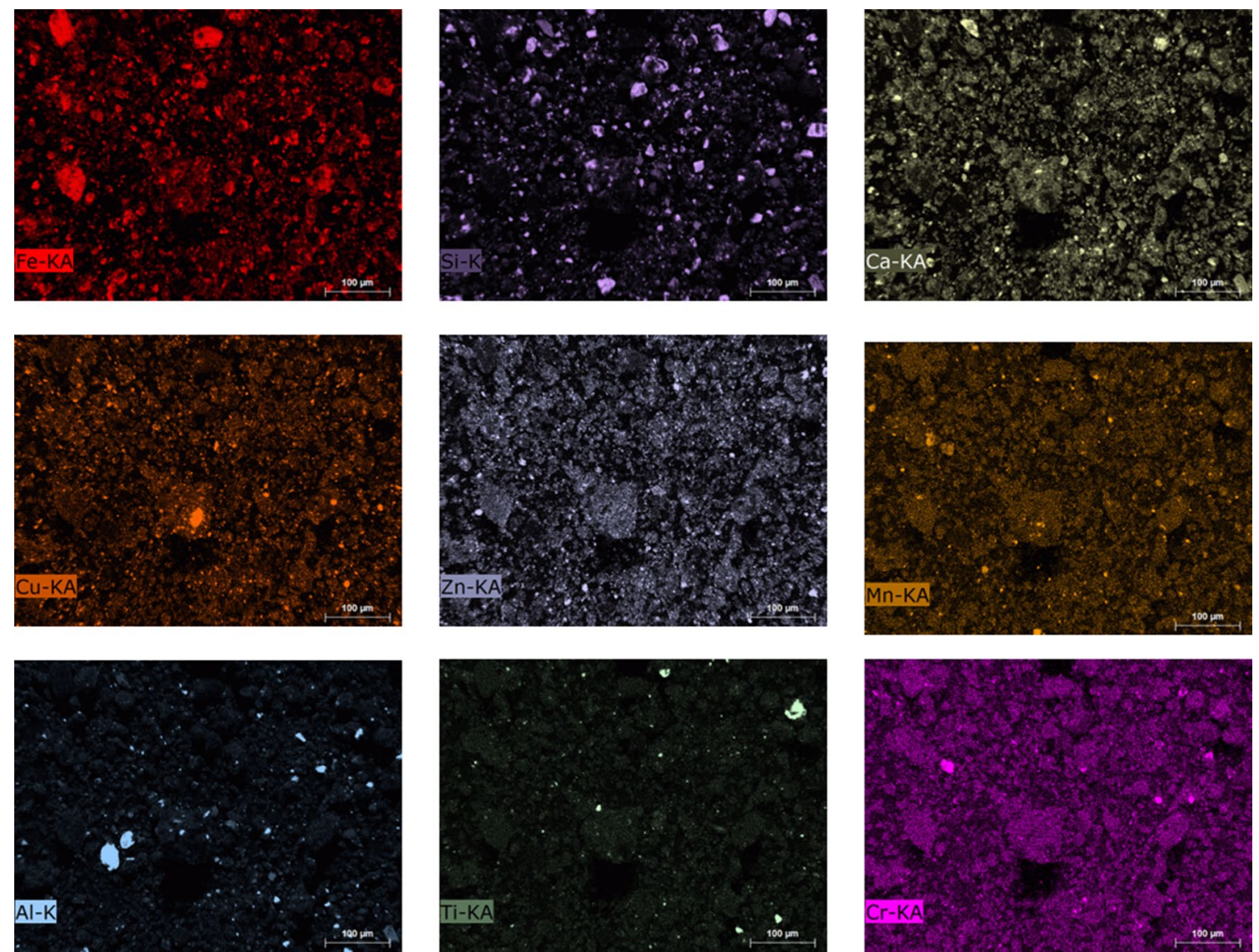

Fig. 8 Elemental mapping of metal concentrate from sample A (from top left to bottom right: $\mathrm{Fe}, \mathrm{Si}, \mathrm{Ca}, \mathrm{Cu}, \mathrm{Zn}, \mathrm{Mn}, \mathrm{Al}, \mathrm{Ti}$, and $\mathrm{Cr}$ )

responses allowed simultaneous software-based optimization, providing the process conditions for a comparison of different samples. Achieved enrichments and yields at the example of copper were in the range of 2.4-6.2 and 23-41\%. However, also high copper enrichment of 15 was achievable at low yields of $2 \%$. This fraction was further characterized by XRD and SEM-EDX revealing mostly oxide species. The most relevant property influencing density separation efficiency was the particle size. Low $\mathrm{d}_{50}$ values were beneficial due to a likely higher degree of heavy metal liberation. The use of wet shaking tables could make sense as supplement for the treatment of the fine fraction in bottom ash treatment plants if these key performance indicators can be improved. For further improvement of heavy metal enrichment and yield, dry-discharged or non-aged wet-discharged bottom ash might be considered in future studies.

Supplementary Information The online version contains supplementary material available at https://doi.org/10.1007/s10163-021-01325-1.

Acknowledgements This research was funded by the ERA-MIN2 program (Research and innovation program on raw materials for the sustainable development and the circular economy, under the ERA-NET Cofund scheme on Raw Materials) for the project "BASH-TREAT.
Optimization of bottom ash treatment for an improved recovery of valuable fractions" (ERA-MIN ID 157), with support given by the German Federal Ministry of Education and Research (BMBF, FKZ 033RU005 A-C) and the Italian Ministry of Education, University and Research (MIUR). The authors are thankful to the project partners Heidemann Recycling $\mathrm{GmbH}$ and Sysav Utveckling AB. In addition, we would like to thank for laboratory analyses, which were carried out by Bianca Coesfeld, Katja Nordhauß and Maren Riedel.

Funding Open Access funding enabled and organized by Projekt DEAL.

Open Access This article is licensed under a Creative Commons Attribution 4.0 International License, which permits use, sharing, adaptation, distribution and reproduction in any medium or format, as long as you give appropriate credit to the original author(s) and the source, provide a link to the Creative Commons licence, and indicate if changes were made. The images or other third party material in this article are included in the article's Creative Commons licence, unless indicated otherwise in a credit line to the material. If material is not included in the article's Creative Commons licence and your intended use is not permitted by statutory regulation or exceeds the permitted use, you will need to obtain permission directly from the copyright holder. To view a copy of this licence, visit http://creativecommons.org/licenses/by/4.0/. 


\section{References}

1. Abis M, Bruno M, Kuchta K, Simon F-G, Grönholm R, Hoppe M, Fiore S (2020) Assessment of the synergy between recycling and thermal treatments in municipal solid waste management in Europe. Energies 13:1-15. https://doi.org/10.3390/en13236412

2. Neuwahl F, Cusano G, Gómez-Benavides J, Holbrook S, Roudier S (2019) Best available techniques (BAT) reference document for waste incineration: industrial emissions directive 2010/75/EU (Integrated Pollution Prevention and Control). Publications Office of the European Union, Luxembourg

3. Bayuseno AP, Schmahl WW (2010) Understanding the chemical and mineralogical properties of the inorganic portion of MSWI bottom ash. Waste Manage 30:1509-1520. https://doi.org/10. 1016/j.wasman.2010.03.010

4. Huber F, Blasenbauer D, Aschenbrenner P, Fellner J (2020) Complete determination of the material composition of municipal solid waste incineration bottom ash. Waste Manage 102:677-685. https://doi.org/10.1016/j.wasman.2019.11.036

5. Huber F, Korotenko E, Šyc M, Fellner J (2020) Material and chemical composition of municipal solid waste incineration bottom ash fractions with different densities. J Mater Cycles Waste 23:394-401. https://doi.org/10.1007/s10163-020-01109-Z

6. van de Wouw PMF, Loginova E, Florea MVA, Brouwers HJH (2020) Compositional modelling and crushing behaviour of MSWI bottom ash material classes. Waste Manage 101:268-282. https://doi.org/10.1016/j.wasman.2019.10.013

7. Chandler AJ, Eighmy TT, Hartlen J, Hjelmar O, Kosson DS, Sawell SE, van der Sloot HA, Vehlow J (1997) Municipal solid waste incineration residues: an international perspective on characterisation and management of residues from municipal solid waste incineration. Elsevier, Amsterdam

8. Wei YM, Shimaoka T, Saffarzadeh A, Takahashi F (2011) Mineralogical characterization of municipal solid waste incineration bottom ash with an emphasis on heavy metal-bearing phases. J Haz Mat 187:534-543. https://doi.org/10.1016/j.jhazmat.2011.01. 070

9. Hyks J, Astrup T (2009) Influence of operational conditions, waste input and ageing on contaminant leaching from waste incinerator bottom ash: a full-scale study. Chemosphere 76:1178-1184. https://doi.org/10.1016/j.chemosphere.2009.06.040

10. Meima JA, Comans RNJ (1997) Overview of geochemical processes controlling leaching characteristics of MSWI bottom ash. In: Goumans JJJM, Senden GJ, van der Sloot HA (eds) Studies in environmental science, vol 71. Elsevier, pp 447-457

11. Chandler AJ, Eighmy TT, Hartlen J, Hjelmar O, Kosson DS, Sawell SE, van der Sloot HA, Vehlow J (1997) Chapter 9.1 Physical characteristics of bottom ash. In: Municipal solid waste incineration residues, The International Ash Working Group, in Series in Environmental Science, vol. 67. Elsevier, Amsterdam: 342-368

12. Speiser C, Baumann T, Niessner R (2001) Characterization of municipal solid waste incineration (MSWI) bottom ash by scanning electron microscopy and quantitative energy dispersive X-ray microanalysis (SEM/EDX). Fresenius J Anal Chem 370:752-759

13. Šyc M, Simon F-G, Hyks J, Braga R, Biganzoli L, Costa G, Funari V, Grosso M (2020) Metal recovery from incineration bottom ash: state-of-the-art and recent developments. J Haz Mat 393:1-17. https://doi.org/10.1016/j.jhazmat.2020.122433

14. Holm O, Simon F-G (2017) Innovative treatment trains of bottom ash from municipal solid waste incineration in Germany. Waste Manage 59:229-236. https://doi.org/10.1016/j.wasman.2016.09. 004

15. Blasenbauer D, Huber F, Lederer J, Quina MJ, Blanc-Biscarat D, Bogush A, Bontempi E, Blondeau J, Chimenos JM, Dahlbo H, Fagerqvist J, Giro-Paloma J, Hjelmar O, Hyks J, Keaney J,
Lupsea-Toader M, O’Caollai CJ, Orupõld K, Pająk T, Simon F-G, Svecova L, Šyc M, Ulvang R, Vaajasaari K, van Caneghem J, van Zomeren A, Vasarevičius S, Wégner K, Fellner J (2020) Legal situation and current practice of waste incineration bottom ash utilisation in Europe. Waste Manage 102:868-883. https://doi. org/10.1016/j.wasman.2019.11.031

16. Kalbe U, Simon F-G (2020) Potential use of incineration bottom ash in construction: evaluation of the environmental impact. Waste Biomass Valori 11:7055-7065. https://doi.org/10.1007/ s12649-020-01086-2

17. Steketee JJ, Duzijn RF, Born JGP (1997) Quality improvement of MSWI bottom ash by enhanced aging, washing and combination processes. In: Goumans JJJM, Senden GJ, van der Sloot HA (eds) Waste materials in construction, studies in environmental science, vol 71. Elsevier, Netherlands, pp 13-23

18. Abis M, Bruno M, Simon F-G, Grönholm R, Hoppe M, Kuchta K, Fiore S (2021) A novel dry treatment for municipal solid waste incineration bottom ash for the reduction of salts and potential toxic elements. Materials 14:1-15. https://doi.org/10. 3390/ma14113133

19. Astrup T, Muntoni A, Polettini A, Pomi R, Van Gerven T, Van Zomeren A (2016) Treatment and reuse of incineration bottom ash. In: Prasad MNV, Shih K (eds) Environmental materials and waste, resource recovery and pollution prevention. Academic Press, Amsterdam, pp 607-645

20. Bunge R (2018) Recovery of metals from waste incineration bottom ash. In: Holm O, Thome-Kozmiensky E (eds) Removal, treatment and utilisation of waste incineration bottom ash. TK Verlag, Neuruppin, pp 63-143

21. Holm O, Wollik E, Bley TJ (2018) Recovery of copper from small grain size fractions of municipal solid waste incineration bottom ash by means of density separation. Int J Sustain Eng 11:250-260. https://doi.org/10.1080/19397038.2017.1355415

22. Back S, Sakanakura H (2021) Distribution of recoverable metal resources and harmful elements depending on particle size and density in municipal solid waste incineration bottom ash from dry discharge system. Waste Manag 126:652-663. https://doi. org/10.1016/j.wasman.2021.04.004

23. Back S, Ueda K, Sakanakura H (2020) Determination of metalabundant high-density particles in municipal solid waste incineration bottom ash by a series of processes: sieving, magnetic separation, air table sorting, and milling. Waste Manag 112:1119. https://doi.org/10.1016/j.wasman.2020.05.002

24. Ernawati R, Idrus A, Petrus HTBM (2018) Study of the optimization of gold ore concentration using gravity separator (shaking table): case study for LS epithermal gold deposit in Artisanal Small scale Gold Mining (ASGM) Paningkaban, Banyumas, Central Java. IOP Conf Ser Earth Environ Sci 212:012019. https://doi.org/10.1088/1755-1315/212/1/012019

25. Arias NR, Arias SR, Rivera LM, Oliveros MM (2021) Recovery of copper through concentration processes from ashes produced by WEEE pyrolysis. J Pure Appl Res Eng Technol 19:163-171. https://doi.org/10.22201/icat.24486736e.2021.19.2.1583

26. Falconer A (2003) Gravity separation: old technique/new methods. Phys Sep Sci Eng 12:31-48. https://doi.org/10.1080/14786 47031000104293

27. Wills BA, Finch JA (2016) Gravity concentration. In: Wills BA, Finch JA (eds) Wills' Mineral processing technology. Butterworth-Heinemann, Boston, pp 223-244

28. Tripathy SK, Ramamurthy Y, Singh V (2011) Recovery of chromite values from plant tailings by gravity concentration. J Miner Mater Charact Eng 10:13-25. https://doi.org/10.4236/jmmce. 2011.101002

29. Youssef M, Abd El-Rahman M, Helal N, El-Rabiei M, Elsaidy S (2009) Optimization of shaking table and dry magnetic 
separation on recovery of Egyptian placer cassiterite using experimental design technique. J Ore Dress 11:1-9

30. Schiffers A: Technische und wirtschaftliche Aspekte der Goldaufbereitung in Kieswerken (2009) RWTH Aachen University

31. Mackay D, Simandl G, Luck P, Grcic B, Li C, Redfearn M, Gravel J (2014) Concentration of carbonatite indicator minerals using a Wilfley gravity shaking table: A case history from the Aley carbonatite, British Columbia, Canada. In: Geological Fieldwork. British Columbia Ministry of Energy and Mines, British Columbia Geological Survey Paper: 189-195

32. Boehnke J, Stockinger G (2019) Möglichkeiten und Grenzen der Nassaufbereitung feiner MVA Rostaschen. Mineralische Nebenprodukte und Abfälle 6. TK-Verlag, Neuruppin, pp 166-187

33. Fedotov PK, Senchenko AE, Fedotov KV, Burdonov AE (2021) A study of gold ore for processability by gravity separation techniques. Tsm. https://doi.org/10.17580/tsm.2021.02.01

34. Nie C-C, Shi S-X, Lyu X-J, Wu P, Wang J-X, Zhu X-N (2021) Settlement behavior and stratification of waste printed circuit boards particles in gravitational field. Resour Conserv Recycl 170:105615. https://doi.org/10.1016/j.resconrec.2021.105615

35. Xing W, Hendriks C (2006) Decontamination of granular wastes by mining separation techniques. J Clean Prod 14:748-753. https://doi.org/10.1016/j.jclepro.2004.05.007

36. Sun X, Yi Y (2021) Acid washing of incineration bottom ash of municipal solid waste: effects of $\mathrm{pH}$ on removal and leaching of heavy metals. Waste Manage 120:183-192. https://doi.org/10. 1016/j.wasman.2020.11.030

37. Al-Ghouti MA, Khan M, Nasser MS, Al Saad K, Heng OE (2021) A novel method for metals extraction from municipal solid waste using a microwave-assisted acid extraction. J Clean Prod 287:125039. https://doi.org/10.1016/j.jclepro.2020.125039
38. Pfandl K, Küppers B, Scheiber S, Stockinger G, Holzer J, Pomberger R, Antrekowitsch H, Vollprecht D (2019) X-ray fluorescence sorting of non-ferrous metal fractions from municipal solid waste incineration bottom ash processing depending on particle surface properties. Waste Manage Res 38:111-121. https://doi.org/10. 1177/0734242X19879225

39. van der Veen AMH, Nater DAG (1993) Sample preparation from bulk samples: an overview. Fuel Process Technol 36:1-7. https:// doi.org/10.1016/0378-3820(93)90003-m

40. Sivamohan R, Forssberg E (1985) Principles of tabling. Int J Miner Process 15:281-295. https://doi.org/10.1016/03017516(85)90046-8

41. Anderson MJ, Whitcomb PJ (2014) Practical aspects for designing statistically optimal experiments. J Stat Sci Appl 2:85-92. https:// doi.org/10.17265/2328-224X/2014.03.001

42. Design Expert (2005) “Version 12.0.12. Stat-Ease," Design Expert Inc., Minneapolis, USA

43. Meima JA, van der Weijden RD, Eighmy TT, Comans RNJ (2002) Carbonation processes in municipal solid waste incinerator bottom ash and their effect on the leaching of copper and molybdenum. Appl Geochem 17:1503-1513. https://doi.org/10.1016/S08832927(02)00015-X

44. Yang Z, Lü F, Zhang H, Wang W, Shao L, Ye J, He P (2021) Is incineration the terminator of plastics and microplastics? J Haz Mat 401:123429. https://doi.org/10.1016/j.jhazmat.2020.123429

Publisher's Note Springer Nature remains neutral with regard to jurisdictional claims in published maps and institutional affiliations. 